\title{
Transitional cell carcinoma in an ileal conduit
}

\author{
F.T. Curran and W.J. Fuggle \\ Department of Urology, Selly Oak Hospital, Raddlebarn Road, Birmingham B29 6JD, UK.
}

\begin{abstract}
Summary: Following cystectomy for transitional cell carcinoma a 63 year old woman developed recurrent tumours in the upper urinary tract and ileal conduit, suggesting that malignant transitional cells can auto-implant in ileal epithelium. This phenomenon has not been previously reported. We illustrate the value of retrograde urogram via an ileal conduit following cystectomy for cancer.
\end{abstract}

\begin{abstract}
Introduction
We report the first recorded case of a patient with transitional cell carcinoma in an ileal conduit with concurrent transitional cell carcinoma of the upper urinary tract. The patient, 4 years following cystectomy for transitional cell carcinoma of the bladder, developed multiple tumours in the upper urinary tract as well as a tumour in the ileal conduit.
\end{abstract}

\section{Case report}

A 63 year old woman was seen in January 1978 with a 6 week history of painless haematuria. Intravenous urogram showed normal upper tracts and two filling defects in the bladder. At cystoscopy several papillary tumours were seen on the base of the bladder and open cystodiathermy was carried out. Histological examination of the resected tumours showed a grade I papillary carcinoma of the bladder. At check cystoscopy 4 months later no recurrent bladder tumour was seen.

Over the following 3 years recurrent papillary bladder tumours were fulgurised. In addition, in March 1980, October 1980 and February 1981 widespread recurrences were treated with intravesical ethoglucid, triethylenethiophosphoramide (Thiotepa) and adriamycin respectively.

By July 1981, she had again developed extensive recurrence of her bladder tumour, clinically stage $T 1$. She therefore underwent total cystectomy and formation of ileal conduit. Histological examination of the bladder showed a papillary transitional cell carcinoma grade I - II with no invasion of muscle.

When reviewed in April 1985 she had had haematuria for 3 weeks. Intravenous urogram showed filling defects in the right renal pelvis, right ureter and

Correspondence: F.T. Curran F.R.C.S. (Ed.)

Accepted: 3 January 1986 in the proximal end of the ileal conduit. Retrograde examination via the ileal conduit using Conray 280 gave a clearer demonstration of these abnormalities (Figure 1). Conduitoscopy confirmed the presence of a large tumour which was arising from the ileal mucosa and not from the ileo-ureteric anastomosis. Right nephro-ureterectomy, conduitectomy and formation of new ileal conduit was performed.

The kidney, pelvis, ureter and ileal conduit were opened longitudinally in continuity. There were papillary tumours in the renal pelvis, upper and lower ureters and a large tumour in the ileum which was not contiguous with the uretero-ileal anastomosis. Histological examination showed the upper urinary tract tumours to be grade I and II papillary transitional cell carcinomas, which were non-invasive. The ileal tumour was of similar grade but was invading the submucosa and muscularis propria. There was a zone of flattened epithelium around the carcinoma which was of indifferent type abutting onto normal ileal mucosa.

\section{Discussion}

The patient we have reported is interesting for two reasons. Firstly, she developed extensive transitional cell carcinoma of the right upper urinary tract 4 years after total cystectomy for transitional cell carcinoma of the bladder. Secondly, there was transitional cell tumour in the ileal conduit when surrounding mucosa was that of normal ileum. These tumours were histologically identical to those found in the bladder.

Over $50 \%$ of patients with renal pelvic or ureteral carcinomas have, or subsequently develop, bladder carcinoma and the need for long-term follow-up is well appreciated (Grabstald et al., 1971; Williams \& Mitchell, 1973). The incidence of upper tract carcinoma following bladder tumours, however, is much lower. Zincke et al. (1984) found an incidence of only $3.3 \%$ in

(C) The Fellowship of Postgraduate Medicine, 1986 


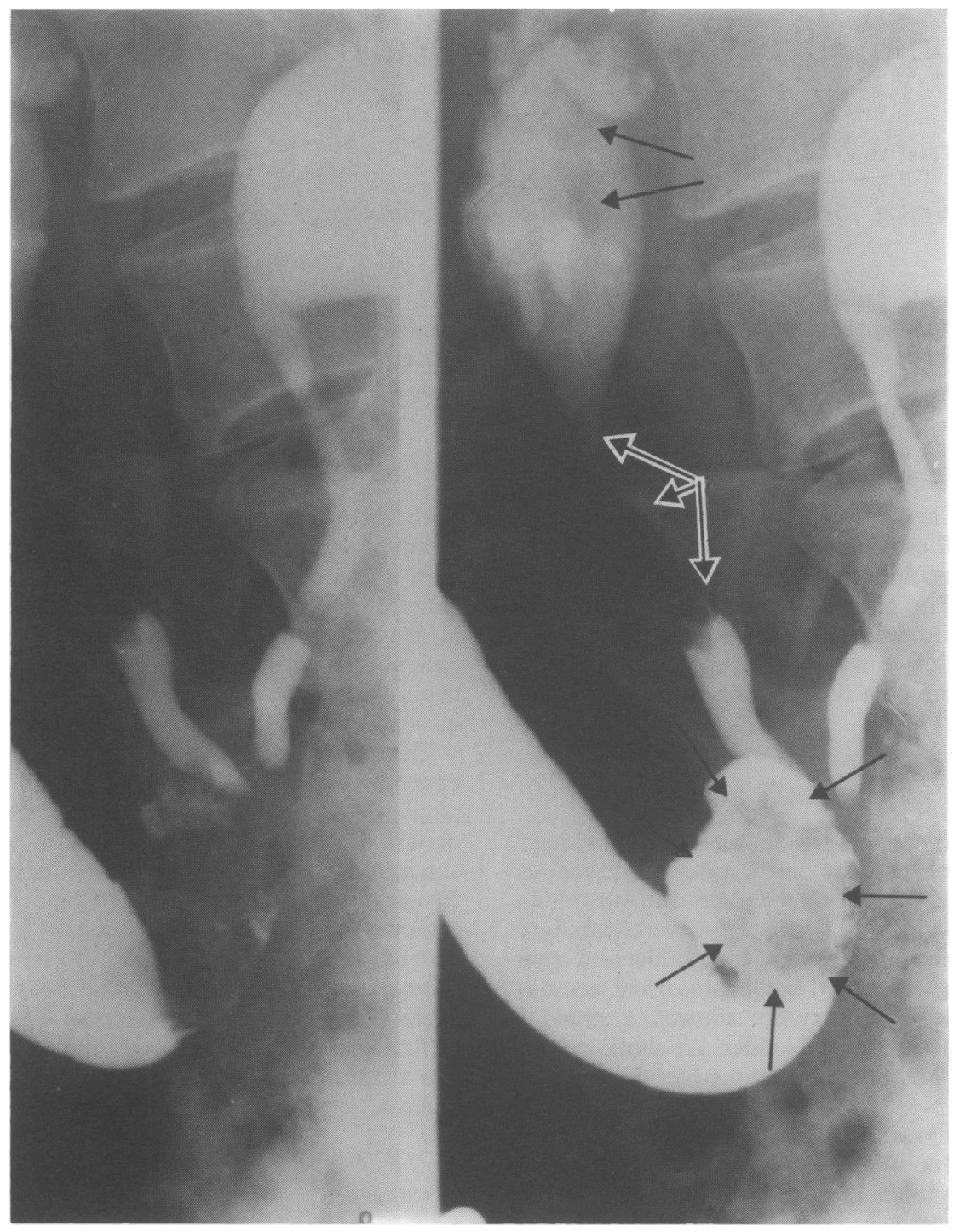

Figure 1 Retrograde urogram showing large papillary tumour in ileal conduit and filling defects in the right ureter and renal pelvis.

a study of $\mathbf{4 2 5}$ patients following radical cystectomy and the interval between cystectomy and the appearance of the upper tract tumour ranged from 8 to 100 months (mean 40 months).

There have been 2 previous reports of transitional cell carcinoma arising in an ileal conduit. The patient reported by Rubin et al. (1979) had had a cystectomy for transitional cell carcinoma of the bladder $6 \frac{1}{2}$ years earlier and there was no tumour in the upper urinary tracts. The authors attributed the presence of the tumour to surgical implantation. Wajsman et al. (1975) reported a similar case.

There are 4 other reports of transitional cell carcinoma involving an ileal conduit but these all arose from the uretero-ileal anastomosis. Solway et al. (1972), reported 2 cases, and Allan (1976) and Banigo et al (1975) reported one case each. The patient described by Allan also had recurrent transitional cell carcinoma of the left renal pelvis and ureter.

Grabstald (1974) reported a patient with tran- 
sitional cell carcinoma around the cutaneous stoma of an ileal conduit 4 years after radical cystectomy for a histologically similar tumour. He attributed its occurrence to mechanical implantation of tumour cells whilst fashioning the stoma.

Surgical implantation seems unlikely to have been the cause of the ileal tumour in our case as the tumour did not arise from the anastomosis and because there were concurrent tumours in the right renal pelvis and right ureter which could not have been due to implantation. The concept of multicentric tumour neogenesis in urothelium (Kaplan et al., 1951; Zincke et al., 1984) explains the upper tract tumours but not that in the ileal conduit. Transitional metaplasia of columnar epithelium is not known to occur and studies of the histology of intestinal urinary conduits which had been in place for up to 10 years showed no evidence of adaptive metaplastic transformation; only a chronic inflammatory reaction was observed (Garner et al., 1975). The most likely explanation is that this ileal conduit tumour was an auto-implant from the naturally friable papillary tumours in the pelvis and ureter.

\section{References}

ALLAN, D.M. (1976). Recurrent transitional cell carcinoma complicating ileal conduit. British Journal of Urology, 48, 60 .

BANIJO, O.G., WAISMAN, J. \& KAUFMAN, J.J. (1975). Papillary (transitional) carcinoma in an ileal conduit. Journal of Urology, 114, 626.

CAMPBELL, J.E., OLIVER, J.A. \& MCKAY, D.E. (1965). Dynamics of ileal conduits. Radiology, 85, 338.

GARNER, J.W., GOLDSTEIN, A.M.B. \& COSGROVE, M.D. (1975). Histologic appearance of the intestinal urinary conduit. Journal of Urology, 114, 854.

GRABSTALD, H. (1974). Carcinoma of ileal bladder stoma. Journal of Urology, 112, 332.

GRABSTALD, H., WHITMORE, W. FL. \& MELAMED, M.R. (1971). Renal pelvic tumours Journal of the American Medical Association, 218, 845.

KAPLAN, J.H., MCDONALD, J.R. \& THOMPSON, G.J. (1951).
Thus, patients who have had cystectomy for cancer may develop tumours in the upper urinary tract or in the ileal conduit, sometimes after an interval of many years. Continued follow-up is therefore recommended. Urine cytology has been shown to be useful (Rubin et al., 1979; Solway et al., 1972; Zincke et al., 1984).

Retrograde studies via the ileal conduit gave valuable information in our patient and other authors have found this investigation to be more useful than intravenous urogram (Allan, 1976; Rubin et al., 1979; Zincke et al., 1984); reflux from an ileal conduit into the ureters occurs frequently enough to be regarded as a normal finding (Campbell et al., 1965).

\section{Acknowledgements}

We would like to thank Mr C.H. Young, Consultant Urologist, for allowing us to report his patient, and Dr Ann Savage, Consultant Histopathologist, for help and advice.

Multicentric origin of papillary tumours of the urinary tract. Journal of Urology, 66, 792.

RUBIN, B.E., RODRIQUEZ, E., MANGASARIAN, R., CUMMINGS, J. \& KWART, A. (1979). Recurrent transitional cell carcinoma in an ileal conduit. Urologic Radiology, $1,61$.

SOLWAY, M.S., MYERS, G.H., BURDICK, J.F. \& MALMGREN, R.A. (1972). Ileal conduit exfoliative cytology in the diagnosis of recurrent cancer. Journal of Urology, 107, 835.

WAJSMAN, Z., BAUMGARTNER, G. \& MERRIN, C. (1975). Transitional cell carcinoma of ileal loop following cystectomy. Urology, 5, 255.

WILLIAMS, C.B. \& MITCHELL, J.P. (1973). Carcinoma of the renal pelvis: a review of 43 cases. British Journal of Urology, 45, 370.

ZINCKE, H., GARBEFF, P.J. \& BEAHRS, J.R. (1984). Upper urinary tract transitional cell cancer after radical cystectomy for bladder cancer. Journal of Urology, 131, 50. 